\title{
The Role of Informal Learning on the Teaming Process of Engineering
}

\author{
Students
}

\author{
Dilia Alcalde, MBA, Med and Stephanie Adams, PhD \\ University of Nebraska- Lincoln
}

Background

Of special importance in to days fast pace organizations is the fact that employers seek individuals exhibiting new skills and capabilities and who are "work ready," capable of performing at high levels upon employment rather than having to undergo a long-term orientation training, and maturing. One of these important skills is teamwork skills ${ }^{1,2}$. Eighty two percent $(82 \%)$ of companies with 100 or more employees use teams ${ }^{3}$, new job designs and practices require teamwork ${ }^{4}$ and organizations consider teamwork skills a prerequisite for the graduates they hire ${ }^{1,2,5}$. Unfortunately, a large number of newcomers to organizations do not posses the required skills and capabilities. Specifically, as Adams, et al., (2002) point out, "engineering students are not effectively prepared to work in teams.... A gap exists between the mastery of teaming skills expected and those demonstrated by new engineering graduates."6

Research on teams in the corporate field has produced a body of literature that among other things identifies team design, and critical team processes or teamwork skills and behaviors related to effective team performance ${ }^{7,8,9,10,11,12,13,14}$ As result, classroom training, seminars, workshops and on the job training have been developed and used by practitioners to try and develop effective teams.

In the educational field, research has also produced a body of literature that suggests recommendations for team design and team processes focusing on learning as the main outcome $e^{9,15,16,17}$ As result, forms of active learning (cooperative learning, collaborative learning) have been introduced into the curricula. Studies of cooperative learning have served two purposes; investigating if these approaches develop teamwork skills and investigating the relationship of team processes to team performance ${ }^{18}$ 
Although research in teams has identified important aspects of teamwork such as skill dimensions, team processes and behaviors related to effective teams, the aspect of how team members individually and collectively learn from their social interactions, discourse and resources, has been overlooked in this research ${ }^{18,19,20}$. This aspect is critical for the understanding and development of teams, teaming skills and team performance.

Informal learning, a concept introduced in the late 50's by Malkon Knowles, has been defined in general as a contextual learning, not highly structured, that occurs as a result of some external or internal trigger and an experience, and can take place despite an environment not highly conducive to learning. It includes incidental learning, which is an unintentional learning that occurs as a by-product of another activity.

Although originated in education, informal learning research has been primarily conducted in the work place. This may be due to the fact that even though informal learning may occur in educational settings, the concept of "informal learning" contrasts with the "formal learning" approach of education of abstract and broad conceptual subjects.

Studies on informal learning in the workplace suggest that people learn everyday doing work-related activities through the social interactions, sharing of ideas and resources and that this learning leads to improvements and should complement formal learning ${ }^{21,22}$. This research has also identified that teaming activities are a critical source for informal learning. In line with these ideas, informal learning occurs during the social interactions, sharing of ideas and resources that go on in any team experience.

Taking into consideration the existing gap between the mastery of teaming skills expected and those demonstrated by new engineering graduates, the study main focus is to explore how informal leaning of teaming skills occurs in engineering teaming experiences. In doing so the results of the study are expected to highlight important aspects that will further contribute to close the gap between the acquisition and mastering of teaming skills by engineering students.

Therefore, the purpose of this study is to explore the role that informal learning has on the teaming process. Specifically we are interested in exploring:

(1) how engineering students informally learn teaming skills during a teaming experience.

(2) what critical teaming skills do engineering students informally learn during a teaming experience.

(3) how engineering students perceive informal learning - in a teaming experience- related to formal learning

With this purpose in mind, the study is guided by one primary question and six secondary questions.

Primary Question:

What is the role of informal learning on the teaming process? 
Secondary Questions:

- How students describe informal learning experiences within the team?

- How students learn teaming skills in a team experience?

- How consciously aware are students of their informal learning?

- What informal learning experiences/events, in a team experience, students perceive as valuable to the teaming process?

- What informally acquired teaming skills, students perceive as valuable to the teaming process?

- How students perceive informal learning in relation to formal learning?

Terminology

For purposes of this study, Students- refer to engineering students enrolled in IMSE 305 course at the University of Nebraska-Lincoln during the first semester 2004.

Teaming skills- refers to team member abilities to effectively deal with relationship and task oriented situations that arise during a team experience.

Informal learning - refers to the acquisition/ construction and sharing of information and meanings through the individual's daily activities and interaction with people or the context. Informal learning experiences/events- refers to non structured events/ activities (e.g. discourse, interaction with other individuals, interaction with objects, collaboration) providing learning. Teaming experience- refers to experience of working in a team.

Teaming process- refers to the relationship oriented and task oriented processes the team goes through in becoming a team and accomplishing a task.

Methodology

This study uses a qualitative methodology framed under a social constructivism perspective of learning. A Qualitative methodology will allow a rich understanding of the phenomena by letting aspects of importance for learning and teaming process emerge form the natural setting. In addition, framing the study under a social constructivism theoretical perspective helps place an equal emphasis on context and learning. Social constructivism perceives learning as a social process, not a process that only takes place inside our minds, or a passive development of our behaviors that is shape by external forces ${ }^{23}$. Meaningful learning occurs when individuals are engaged in social activities. Knowledge is a product of human interaction. Knowledge is a social effort and meaning is produced by everyday, ongoing actions of a community of practice. Individuals make meanings through the interactions with each other and with the environment they live in. Reality is constructed by our own activities. Reality is not something we can discover because it does not pre-exist prior to our social invention of it.

Qualitative research use methods for collecting data that make "situations come alive" and "keep investigators close to the data". In order to understand the perspectives and responses of the students presenting an accurate portrayal, multiple data techniques are $u_{s e d}{ }^{24}$. They include: 
interviews, observations and document research. In this study, observations, formal and informal interviews, and journal research are conducted.

Observation is the process of gathering first hand information by observing people and places at a research site ${ }^{25}$. It affords the opportunity to record information as it occurs in a setting. In this study we are interested in observing possible events, interactions, activities etc., from which people may be able to learn from in a natural setting. For this study, the process of observation consists of examining the videotaped team meetings. For the observations an observational protocol was designed. This observational protocol is a form designed by the researchers for taking notes during observation and writing reflective notes about methodological questions, concerns, and ideas.

Records of observations is maintained in the observational protocol containing notes taken during the observation and reflective notes of the researcher's methodological questions, concerns, and ideas. The main researcher takes a non-participatory observer role, taking records and notes without becoming involved in the activities of the participants.

Denzin (1989) sees interviewing as "face to face verbal interchanges in which one person attempts to elicit information or expressions of opinions or belief from another person or persons $^{26}$ “. Interviews allow informants to express their own understanding in their own terms. Interviews range from highly structured close end questionnaires to open ended conversations. For this study a semi-structured interview is used. A semi-structure interview allows for emerging topics to come out. With this in mind, a tentative set of questions exploring several issues of interests is outlined in an interview protocol. Nevertheless, the wording and the sequence of the questions can change as the interview proceeds. This allows the researcher to adapt to the natural setting.

Following each interview the researcher records reflective comments. Interviews are audio taped for further detailed analysis. Content of the interview and reflection comments are typed for further coding. Records from the interviews are kept in three ways, through audiotape, through record of reflective comments and through transcriptions of interview. A preliminary coding is done by noting categories in the margins of interview transcriptions.

Transcriptions of interviews will be returned to the informants for verification. Following the return of the interviews from the informants, the researcher will revise the preliminary coding and develop sub-codes and themes.

Participant's written journals containing their entries about ideas, concerns, questions, etc., related to their teamwork will be collected in the middle and end of the semester.

\section{Data Analysis Procedures}

Participants involved in the study are 32 registered engineering students enrolled in Introduction to Engineering Management, IMSE 305 course at the University of Nebraska-Lincoln during the first semester 2004. The objective of this class is to expose the student to a broad range of 
concepts, methods and practices in the field of management, and how these are applied in the engineering context. The students voluntarily agreed to participate. From the beginning of the semester students were randomly assigned to teams of 4 . As a result 8 teams were formed. During the semester the teams take part in several class team activities and two main team projects. Teams meeting are held in a room specially equipped for audio and videotaping and with all the resources necessary for the team meetings. Four cameras located in the 4 corners of the room provide four (4) views of the team meetings. The room is equipped with a round table, books related to class topics and teams, computers, internet service, TV and telephone. In addition an assistant - to answers to any question) is always present and available in a contiguous room during the team meetings.

An important assumption of qualitative data analysis is that the researcher needs to recognize that his/her views and perspectives rooted in cultural and historical factors ultimately shape his/her interpretation. The data analysis process in qualitative research is primarily inductively informed, going from the particular (detailed data in transcriptions, field notes) to the general (codes and themes). According to Creswell there is no single way to analyze qualitative data; it is an eclectic process in which you are trying to make sense of the information ${ }^{25}$

Analysis of data will be conducted as follows: Initial preparation of the data for analysis will consist on organizing all interviews, observations of videotaped meetings and written journals by participant and team. Content of the interview and reflection comments will be transcribed. After that, transcription of each interview will be sent to each participant for verification of information. Verbatim comments obtained through the observation of meetings and written journals will also be transcribed. With this, the researchers will conduct a preliminary exploratory analysis, obtaining a general sense of the data.

Beyond the general understanding of the data, the researchers need to answer the research question. In order to do that, the researcher will examine the data in detail to develop themes or broad categories of ideas from the data. The development of themes will be done through a coding procedure following the steps below:

1- $\quad$ Reading through all material and writing down ideas that come to mind.

2- $\quad$ Consider the underlying meaning and write it down in two or three words.

3- Cluster similar codes. Look for redundant codes. Reduce the list of codes.

4- $\quad$ Go back to the data and see if new codes emerge.

5- $\quad$ Circle specific quotes from participants that support the codes.

6- $\quad$ Reduce the list of codes to 5-7 similar codes aggregated together to form a major idea or theme.

7- $\quad$ From the coding and the themes, construct a narrative description of the findings.

8- $\quad$ Go back to the data and look for contrary evidence or information that does not support the themes. This is done to present a more realistic representation of the Information.

Work in progress 
To the present, all data from the team meetings has been was videotaped and organized by team. Data from team members' written journals has been collected and organized by team member and team. Informal interviews have been conducted but formal interviews are yet to be conducted. Initial transcription of observations and comments in written journals has been done.

\section{Expected Results}

The researchers expect that the qualitative methodology used in this research reveal specific taken for granted / hidden events, activities, or situations that might provide opportunities for learning teamwork skills. These situations may be for example, observing how a member of the team responds to something said by another team member, clarifying ideas or making mistakes. We also expect to identify from each situation a specific team skill derived from it. For example, learning how to listen or how to solve conflicts could be linked to observing other team member behaviors. At the same time we expect to identify which situations and skills are perceived by the team members to better contribute to the team performance. All this will highlight those events/ behaviors or/and skills that are important to be monitored during the teaming process and that may be considered in a training process. In addition, we expect the results to highlight important aspects as to how to integrate formal and informal learning. Putting all this together, in the study of engineering student teams we expect that the results of the study will further contribute in closing the gap between engineering students' acquisition of teaming skills and the 21 st century organizations' requirements.

1. Overtoom, Ch. (2000). “Employability skills: An update”. (ERIC Digest No. 220). US, Ohio: ducationalResearch Association. (ERIC Document Reproduction Services No. EDO-CE-00-220)

2. Alexander, M. W., \& Stone, S.F. (1997). Student perceptions of teamwork in the classroom: An analysis by gender. "Business Education Forum”, 51(3), 7-10.

3. Gordon, J. (1992). Work teams: How far have they come? "Training”, 29(10), 59-65.

4. Capelli, P., \& Rogosvsky, N. (1994). New work systems and skills requirements. "International Labour Review”, 133(2), 205-220.

5. Dow, K. O. \& Liedtka, J. (1994). What corporations seek in MBA hires: A survey. The Magazine of Graduate Management Admission Council, 2.

6. Adams, S. G., Simon, L., Ruiz, B, Pereira, F. (2002). A pilot study on the performance of student teams in engineering education. "Proceedings of the 2002 American Society for Engineering Educational Annual Conference \& Exposition”.

7. Amason, A.C. (1996). Distinguishing the effects of functional and dysfunctional conflict on strategic decisionmaking: Resolving a paradox for top management teams. "Academy of Management Journal”, 39(1), $123-148$.

8. Jehn, K. (1995). A multimethod examination of the benefits and detriments of intragroup conflict. “Administrative Science Quarterly”, 40(20), 245-382.

9. Keller, R. T. (1994). Technology information processing fit and the performance of R \& D project groups: A test of contingency theory. “Academy of Management Journa”l, 37(1), 169-179.

10. Mullen, B., \& Cooper, C. (1994). The relation between group cohesiveness and performance: An integration. "Psychological Bulletin", 115, 210-227.

11. Oser, R.L., McCallum, G. A., Salas, E., \& Morgan, B. B., Jr. (1989). "Toward a definition of teamwork: An analysis of critical team behavior". In Salas, E. and Cannon-Bowers, J. "Methods, tools and strategies for team training",

12. Seers, A., Petty, M. M., \& Cashman, J.F. (1995). Team member exchange under team and traditional management: A naturally occurring quasi experiment. “Group \& Organization Management”, 20(1), 18-38. 
13. Smith, K. G., Smith, K.A., Olian, J. D. Smis, H. P., Jr., O’Bannon, D. P., \& Scully, J. A. (1994). Top management team demography and process: The role of social integration and communication. "Administrative Science Quarterly". 39, 412-438.

14. Werner, J.M., \& Lester, S. W. (2001). Applying a team effectiveness framework to the performance of student case teams. "Human Resource Development Quarterly", 12(4), 385-402.

15. Baker, L. J. (1995). "The effect of cooperative study groups on achievement of college level computer science programming students". Doctoral dissertation, University of Texas, Austin. UMI dissertation international, No. 9534716.

16. Bosangue, M. (1991). "Achievement effects of collaborative learning in introductory statistics: A time series residual analysi" s. Paper presented at the joint annual meeting of the mathematical association of America/ The American Mathematical society. San Francisco: CA.

17. Springer, L., Stanne M.E., Donovan, S.S. (1999). Effects of small group learning on undergraduates in science, mathematics, engineering, and technology: A meta-analysis. "Review of Educational Research", 69 (1), 21-51.

18. Druskat, V. U., \& Kayes, D. C. (2000). Learning versus performance in short-term project teams. Small Group Research, 31(3).

19. Baker, D., \& Salas, E. (1992). Principles for measuring teamwork skills. "Human Factors", 34, 469-475.

20. Cannon- Bowers, J. A. \& Salas, E., (1990). In Quinonez, M. \& Ehrenstein, A., (Eds.), "Training for a rapid changing workplace: applications of psychological research". 249-279. Washington: American Psychological Association.

21. Bruce, L. (1997). Informal Learning: The new frontier of employee \& organizational development. "Economic Development Review”, 15(4), 12-19.

22. Cofer, D. (2000). "Informal Workplace learning. Practice Application Brief No 10". Clearinghouse on Adult, Career and Vocational Education. Columbus, Ohio.

23. Turnbull, S. (2002). Social Construction Research and Theory Building. In Lynham, S.A. \& Swanson, R. A. (2002). (Eds). "Advances in Developing Human Resources: Theory Building in Applied Disciplines". BerrettKoehler. San Francisco: CA. (pp. 317- 334).

24. Yin, R. K. (1994). “Case Study Research: Design and Methods “. ( $2^{\text {nd }}$ edition). Thousand Oaks: Sage.

25. Creswell, J.W. (1998). "Qualitative Inquiry and Research Design: Choosing Among Five Tradition”. Thousand Oaks: CA. Sage Publications

26. Denzin, N.K. (1989). “The Research Act”. (3 ${ }^{\text {rd }}$ edition). Englewood Cliffs: Prentice Hall.

DILIA M. ALCALDE A. is a doctoral candidate in Education at the University of Nebraska- Lincoln. She holds an M.B.A from the University of Nebraska - Omaha, a M.Ed. from the University of Nebraska - Lincoln and a B.S. in Industrial Engineering from the National University of Tachira - Venezuela.

STEPHANIE G. ADAMS received her Ph.D. from Texas A \& M University in Interdisciplinary Engineering. She holds a M.E degree in Systems Engineering from the University of Virginia and a B.S. degree in Mechanical Engineering from North Carolina A \& T State University. She is currently an Assistant Professor of Industrial and Management System Engineering at the University of Nebraska - Lincoln. 